\title{
The Relationship between Workplace Stressors and Job Strain with Psychological Distress among Employed Malaysian Breast Cancer Survivors
}

\author{
Heng Weay Yong ${ }^{1}$, Hashim Zailina ${ }^{*}$, Jamil O. Zubaidah ${ }^{2}$, Moin Saidi ${ }^{3}$ \\ ${ }^{1}$ Department of Environmental and Occupational Health, Faculty of Medicine and Health Sciences, Universiti Putra Malaysia, Ser- \\ dang, Malaysia; ${ }^{2}$ Department of Psychiatry, Faculty of Medicine and Health Sciences, Universiti Putra Malaysia, Serdang, Malaysia; \\ ${ }^{3}$ Department of Biomedical Sciences, Faculty of Medicine and Health Sciences, Universiti Putra Malaysia, Serdang, Malaysia. \\ Email: ${ }^{*}$ zailina@medic.upm.edu.my
}

Received August $7^{\text {th }}, 2012$; revised September 10 $0^{\text {th }}, 2012$; accepted September $22^{\text {nd }}, 2012$

\begin{abstract}
Evidence showed occupational factors may contribute distress to breast cancer survivors, however, very few studies focused on the occupational factors and job strain among breast cancer survivors. This study examined the relationship between job strain and workplace stressors with psychological distress among employed breast cancer survivors after the completion of their medical treatment. Study subject were outpatients of 2 hospitals and members of 4 breast cancer support groups. They were requested to fill up the Job Content Questionnaires (JCQ), the Hospital Anxiety and Depression Scale (HADS) and the Distress Thermometer (DT) were filled up by the selected respondents. On simple logistic regression, psychological job demand and job strain were significantly associated with anxiety, distress on HADS-T and DT at $(\mathrm{p}<0.001)$. While, psychological job demand $(\mathrm{p}<0.001)$, social support $(\mathrm{p}=0.047)$ and job strain $(\mathrm{p}<0.001)$ were significantly associated with depression. Results showed survivors with high job strain has 4.74 time the odds of having anxiety $(\mathrm{p}<0.001)$. Survivors with high psychological job demand have 8.08 time the odds of getting depression $(\mathrm{p}<0.001)$. On the other hand, social support served as a protective factor of depression, $(\mathrm{p}=0.041)$. Survivors with high psychological job demand were 4.4 time the odds of having distress (HADS-T) $(p=0.012)$. As a conclusion, survivors who experienced high psychological job demand, low social support and high job strain were reported with anxiety, depression or psychological distress.
\end{abstract}

Keywords: Breast Cancer Survivors; Workplace Stressors; Job Strain; Psychological Distress

\section{Introduction}

The outcome of job strain is workplace stress which is considered as a health hazard which arises from interactions of workers and the work demands [1]. Many employers tend to deny the existence of workplace stress. From the employers' perception, workplace stress is a personal problem. Some argues that one should be able to cope with it if they are employed as it is voluntary and it comes with the job, thus, not considered as a workplace hazard. Through time, more researchers found job strain to be a significant health hazard [2,3]. It is a serious health and safety hazard with devastated effects causing mental illnesses to the workers. It is mainly due to the poor match between work demand with work ability and one does not have a reasonable control over work.

Factors from workplace that lead to stress are called workplace stressors. According to Karasek's Job Demand

"Corresponding author.
Model, there are 4 key principal factors contributing to job strain, such as psychological job demand, decision latitude, social support and job insecurity [4]. Psychological job demand refers to the workload, work requirements and organizations' constraints of the workers, while decision latitude includes two dimensions such as skill discretion and decision authority. Skill discretion is the skill and creativity of workers on the job requirement, while decision authority is the flexibility and possibilities of workers to make own decision. The third key factor of workplace stress in job demand model is social support, which refers to support from co-workers, supervisor or management levels and also the interpersonal hostility. The last factor is job insecurity which depends highly on the market requirement for skills and career possibilities.

Strong relationships were found between job strain with emotional distress (anxiety, depression), short term health effects (headache, nausea) and long term health effects (cardiovascular disease, cancer) [5,6]. Previous 
findings showed workplace related factors such as high psychological demand, low decision latitude and interpersonal conflict are common predictor of psychological distress such as anxiety and depression, fatigue and some physical illness, while social support served as a protective factors to psychological distress [7,8]. Job strain and its associated effects lead to poor work performance and poor ability to conduct work task but unfortunately, the presence of job strain is unnoticed $[9,10]$. In Malaysia, a study showed that about $52.3 \%$ of the breast cancer cases were below 50 years [11]. Therefore, most of the survivors were capable of returning to work after their treatment. Many survivors continued employments after diagnosis and treatment, because they believed that employment was an important measure of recovery [12].

Females had significantly higher job strain than male cancer survivors [13]. Many survivors who return to work experienced difficulties due to physical changes, psychological distress associated with cancer as well as the treatment and inadequate work-related support [14]. There is a substantial evidence that occupational and environmental factors contribute to the burden of distress, however, few studies had focused on employed breast cancer survivors. This study examined the relationship between job strain and workplace stressors with psychological distress level of breast cancer survivors after returning to work.

\section{Materials and Methods}

In this study, respondents were made up of breast cancer survivors who were outpatients of 2 hospitals (Hospital Kuala Lumpur and Hospital Seberang Jaya) and members of 4 breast cancer support groups (Segamat, Johor Bahru, Bangi and Ipoh). The respondents were required to complete the Job Content Questionnaires (JCQ), Hospital Anxiety and Depression Scale (HADS) and Distress Thermometer (DT).

Job Content Questionnaire (JCQ) developed by Karasek et al. [7] was used to determine the occupational stressors and levels of job strain at the workplace. This questionnaire was developed based on the demand-control model. The 25 items of JCQ consisted of 4 scales. They are the Psychological Job Demand (5 items), Decision Latitude (9 items), Social Support (8 items) and Job Insecurity ( 3 items). These scales are determinants of job strain. The demand-control model showed high job strain occurred when Psychological Job Demand was high or Decision Latitude was low whereas Social Support served as the protective factors for job strain. Each item in the scales were given scores on a 4-point Likert scale (strongly disagree, disagree, agree and strongly agree; or often, sometimes, rarely and never). The scores were then calculated by using formula for the Job Content Instrument Scale provided in the JCQ.

Psychological distress measured by Hospital Anxiety and Depression Scale (HADS) and Distress Thermometer (DT). HADS is a 14-items scale designed by Zigmond et al. [15] which is used to measure the depression and anxiety levels. This 14 items questionnaire can be divided into 2 subscales, in which 7 items measure the anxiety level (HADS-A) and depression level (HADS-D) respectively. Each item was scored on a 4-point Likert scale of $0-3$, giving each anxiety and depression a maximum score of 21 respectively and a total maximum score of 42 for both. Scores of $<8$ were considered as "noncases" or normal while scores of $\geq 8$ are considered as cases. A total score of $\geq 15$ indicates psychological distress (HADS-T) [16,17].

Distress Thermometer (DT) with problem checklist is a screening measurement developed by National Comprehensive Cancer Network [18], assesses and identifies the psychological distress and its contributing factors. Distress thermometer scale consists of 11 points, which ranged from 0 for no distressed to 10 for extreme distress. Respondents were requested to circle the numbers that represent their distress levels in the past week. Respondents with score of $\geq 4$ were considered as having distress [19]. The problem checklist consists of 33 items which are distress contributing factors. These 33 items are categorized into 5 categories such as practical (4 items), family (3 items), emotional (8 items), spiritual or religious ( 3 items) and physical (23 items).

\section{Results}

\subsection{Socio-Demographic Background and Occupational Information of Respondents}

A total of 150 breast cancer survivors made up of 114 (76.0\%) hospital outpatients and $36(24 \%)$ members of breast cancer support group were recruited. The mean age of respondents were 49.1 (7.1) years. They were mainly Malay (50.6\%), followed by Chinese (44.7\%) and Indian $(4.7 \%)$. The education levels ranged from no formal to tertiary education, the majority with secondary education $(52.0 \%)$. Most were married $(76.0 \%)$, diagnosed with Stage II cancer (57.3\%) and more than half did not have family history of breast cancer $(56.7 \%)$. Majority were employed in the private sector $(60.0 \%)$ followed by the government sector (24.7\%) and selfemployed (25.3\%). Most respondents have normal work hours $(94.0 \%)$ and did not use chemical in their workplace $(85.3 \%)$. They were currently employed for 5.8 (6.4) years and the mean income was RM 2172.8 (1548.4) (Table 1). 
Table 1. Socio-demographic and occupational information of respondents.

\begin{tabular}{|c|c|}
\hline Variables & No. of subjects (\%) \\
\hline \multicolumn{2}{|l|}{ Recruitments of respondents } \\
\hline Hospital & $114(76)$ \\
\hline Support group & $36(24)$ \\
\hline Age (Mean \pm std dev.) & $49.11 \pm 7.10$ \\
\hline \multicolumn{2}{|l|}{ Ethnicity } \\
\hline Malay & $76(50.7)$ \\
\hline Chinese & $67(44.7)$ \\
\hline Indian & $7(4.6)$ \\
\hline \multicolumn{2}{|l|}{ Marital status } \\
\hline Married & $114(76.0)$ \\
\hline Single & $17(11.3)$ \\
\hline Widowed & $13(8.7)$ \\
\hline Divorced & $6(4.0)$ \\
\hline \multicolumn{2}{|l|}{ Education level } \\
\hline No formal education & $6(4.0)$ \\
\hline Primary & $29(19.3)$ \\
\hline Secondary & $78(52.0)$ \\
\hline Tertiary & $37(24.7)$ \\
\hline \multicolumn{2}{|l|}{ Stages of cancer } \\
\hline Stage I & $64(42.7)$ \\
\hline Stage II & $86(57.3)$ \\
\hline \multicolumn{2}{|l|}{ Family history of breast cancer } \\
\hline Yes & $65(43.3)$ \\
\hline No & $85(56.7)$ \\
\hline $\begin{array}{l}\text { Duration of employment (years) } \\
\text { (Mean } \pm \text { std dev.) }\end{array}$ & $19.34 \pm 10.32$ \\
\hline \multicolumn{2}{|l|}{ Employment } \\
\hline Private & $90(60.0)$ \\
\hline Government & $37(24.7)$ \\
\hline Self-employed & $23(15.3)$ \\
\hline \multicolumn{2}{|l|}{ Shift work } \\
\hline Normal hours & $141(94.0)$ \\
\hline Shift work & $9(6.0)$ \\
\hline \multicolumn{2}{|l|}{ Use of chemical at the workplace } \\
\hline No & $128(85.3)$ \\
\hline Yes & $22(14.7)$ \\
\hline $\begin{array}{l}\text { Current employment (years) } \\
\text { (Mean } \pm \text { std dev.) }\end{array}$ & $5.8 \pm 6.4$ \\
\hline Salary incomes (RM) (Mean \pm std dev.) & $2172.8 \pm 1548.4$ \\
\hline
\end{tabular}

\subsection{Prevalence of Work Stressors and Job Strain}

Most of the respondents reported high psychological job demand (52.7\%), high decision latitude (50.7\%), high social support $(51.3 \%)$ and high job insecurity (56.7\%). While, only $26.0 \%$ reported high job strain (Table 2).

\subsection{Psychological Distress Levels Using HADS and DT}

By using the recommended threshold value of 8 for disorder caseness (including borderline cases), $23.3 \%$ of the respondents were classified as anxious and $19.3 \%$ as depressed, while $22.0 \%$ were distressed (HADS-T $\geq 15$ ) (Table 3). Table 4 shows the distress levels of respondents according to the DT and its checklist. The prevalence of distress was $14.7 \%$ according to the DT. The frequencies of items checked in the checklist were examined by multiple response analysis. The most common problems associated with distressed $(\mathrm{N}=60)$ were those related to family $(70.0 \%)$, followed by emotional problems such as sad, lonely, angry, remorse and disappointed $(65.0 \%)$, physical problems and symptoms such as diarrhea, respiratory difficulties, hot flashes, dryness, insomnia and tiredness $(60.0 \%)$, practical problem such health care, finance, housing and transport (50.0\%) and a few on spiritual or religious such as loss hope or direction in life (15.0\%).

\subsection{Relationship between Work Stressors and Job Strain with Psychological Distress Using Both HADS and DT}

Tables 5-8 showed the statistics on the influence of

Table 2. Distributions of workplace stressors and job strain of respondents.

\begin{tabular}{llll}
\hline Variables & $\mathrm{n}(\%)$ & Median & Range \\
\hline Psychological job demand & & & \\
High & $79(52.7)$ & 32 & $18-45$ \\
Low & $71(47.3)$ & & \\
Decision latitude & & & \\
High & $76(50.7)$ & & $30-80$ \\
Low & $74(49.3)$ & 58 & \\
Social support & & & \\
High & $77(51.3)$ & & \\
Low & $73(48.7)$ & 24 \\
Job insecurity & & & \\
High & $85(56.7)$ & & \\
Low & $65(43.3)$ & 9 & \\
Job strain & & \\
High & $39(26.0)$ & & \\
Low & $111(74.0)$ & \\
\hline
\end{tabular}

$\mathrm{N}=150$. 
Table 3. Distributions of psychological distress levels using HADS.

\begin{tabular}{ccc}
\hline Variables & Frequency (n) & Percentage (\%) \\
\hline HADS & & \\
Anxiety score & & 76.7 \\
Normal $(0-7)$ & 115 & 23.3 \\
Anxious ( $\geq 8)$ & 35 & \\
Depression & & 80.7 \\
Normal $(0-7)$ & 121 & 19.3 \\
Depressed ( $\geq 8)$ & 29 & \\
Psychological Distress & & 78.0 \\
Normal $(0-14)$ & 117 & 22.0 \\
Distressed $(\geq 15)$ & 33 & \\
\hline
\end{tabular}

$\mathrm{N}=150$.

Table 4. Prevalence of distress using DT with checklist.

\begin{tabular}{lcc}
\hline Variables & Frequency (N) Percentage (\%) \\
\hline Psychological distress & 128 & 85.3 \\
Normal & 22 & 14.7 \\
Distressed & & \\
Problem checklist categories (N =60) & 42 & 70.0 \\
Family & 39 & 65.0 \\
Emotional & 36 & 60.0 \\
Physical & 30 & 50.0 \\
Practical & 9 & 15.0 \\
Spiritual/religious & & \\
\hline
\end{tabular}

Statistical test-multiple response analysis $\mathrm{N}=150$.

selected socio-demographic factors, workplace stressors and job strain on anxiety, depression and distress using both the HADS and DT scales. Simple logistic regression analysis of 2 socio-demographic factors and 5 workplace stressors showed psychological job demand and job strain were significantly associated with anxiety on HADS-A $(p<0.001)$, distress on HADS-T $(p<0.001)$ and DT ( $<<0.001)$. While, psychological job demand (p $<0.001)$, social support $(\mathrm{p}=0.047)$ and job strain $(\mathrm{p}<$ 0.001 ) were significantly associated with depression on HADS-D. No significant association found between anxiety, depression and distress with job insecurity using both HADS and DT. Statistics showed socio-demographic including employment and stage of cancer were not significantly related to anxiety, depression and distress using both HADS and DT ( $p>0.05)$.

Table 5 shows that job strain is the only predictor for anxiety. Results showed that survivors with high job strain have 4.74 times the odds of having anxiety compared to those with low job strain $(\mathrm{p}<0.001)$. Table 6 shows survivors with high psychological job demand to have 8.08 times the odds of getting depression $(\mathrm{p}<$ $0.001)$. On the other hand, social support was a protective factor for depression $(p=0.041)$.

Tables 7 and 8 shows psychological job demand was predictor for both distress using HADS-T and DT while job strain is the predictor for distress on DT. Survivors with high psychological job demand were 4.4 times the odds of having distress (HADS-T) $(p=0.012)$. Table 8 shows that survivors with high psychological job demand were 6.09 times the odds of having distressed $(p=0.032)$ and survivors with high job strain were 3.17 times the odds of having distressed $(p=0.037)$ on DT. These results reflected a good overall fitness of the model when Hosmer-Lemeshow test $(p>0.05)$ and the area under the ROC curve (AUC) were at least $70 \%$ in the accuracy discrimination of cases (Tables 5-8).

\section{Discussion}

Psychological morbidity including anxiety, depression and distress are common health issues among cancer survivors and can further lead to the hospitalization of distress patients. Thus, there is a need to identify the causes and psychological morbidity of survivors. This study showed the prevalence of anxiety $(7.3 \%)$, depresssion (4.7\%) and distress (22\%) among respondents using the HADS while $14.7 \%$ distressed on DT and this prevalence were lower than other local studies $[20,21]$ and overseas studies $[22,23]$. The difference between the prevalence may be due to the difference in the selection of respondents. This study was among patients who had completed all their medical treatments, however, others were among breast cancer patients who were undergoing chemotherapy. Findings showed the breast cancer patients suffered incredible stress during their treatment thus their distress level were higher, whereas those who had completed the active treatment were less stressed $[24,25]$. Previous study found that the prevalence of anxiety and depression among employed survivors were lower than the unemployed because they felt that they had better chance of improving their social position and securing more social support [26].

Those with anxiety would normally have the coexistence of depression [27]. Similar findings occurred among the Malaysian breast cancer survivors as well, where $15.3 \%$ of the respondents with anxiety were depressed at the same time. However, this prevalence was lower as compared to a data from a National Morbidity Survey which showed that the prevalence of patients with coexistence of depression and anxiety were $51 \%$ [27], however, another local study found a prevalence of $12.5 \%$ for coexistence of depression and anxiety among cancer patients [21]. 
Table 5. Predictor of anxiety using HADS-A models.

\begin{tabular}{|c|c|c|c|c|c|c|}
\hline \multirow{2}{*}{ Variables } & \multicolumn{3}{|c|}{$\mathrm{SLR}^{1}$} & \multicolumn{3}{|c|}{$\mathrm{MLR}^{2}$} \\
\hline & $\mathrm{b}$ & Crude OR $(95 \% \mathrm{CI})$ & $\mathrm{p}$ & $\mathrm{b}$ & Adjusted OR (95\% CI) & $\mathrm{p}$ \\
\hline \multicolumn{7}{|l|}{ Employment } \\
\hline Government & 0.00 & 1 & - & \multirow{3}{*}{-} & \multirow{3}{*}{-} & \multirow{3}{*}{-} \\
\hline Private & -0.72 & $0.49(0.20,1.16)$ & 0.102 & & & \\
\hline Self-employed & -0.31 & $0.74(0.23,2.34)$ & 0.603 & & & \\
\hline \multicolumn{7}{|l|}{ Stage of cancer } \\
\hline Stage I & 0.00 & 1 & - & - & \multirow{2}{*}{-} & \multirow{2}{*}{ - } \\
\hline Stage II & 0.62 & $1.87(0.84,4.16)$ & 0.128 & & & \\
\hline \multicolumn{7}{|c|}{ Psychological Job Demand } \\
\hline Low & 0.00 & 1 & - & \multirow{2}{*}{-} & \multirow{2}{*}{-} & \multirow{2}{*}{ - } \\
\hline High & 1.41 & $4.09(1.71,9.76)$ & $0.002^{* *}$ & & & \\
\hline \multicolumn{7}{|c|}{ Decision Latitude } \\
\hline Low & 0.00 & 1 & - & \multirow{2}{*}{-} & \multirow{2}{*}{-} & \multirow{2}{*}{ - } \\
\hline High & 0.04 & $1.04(0.49,2.22)$ & 0.918 & & & \\
\hline \multicolumn{7}{|l|}{ Social Support } \\
\hline Low & 0.00 & 1 & - & \multirow{2}{*}{ - } & \multirow[b]{2}{*}{-} & \multirow[b]{2}{*}{-} \\
\hline High & -0.60 & $0.13(0.26,1.19)$ & 0.550 & & & \\
\hline \multicolumn{7}{|l|}{ Job Insecurity } \\
\hline Low & 0.00 & 1 & - & \multirow{2}{*}{ - } & \multirow{2}{*}{ - } & \multirow{2}{*}{-} \\
\hline High & -0.28 & $0.76(0.36,1.62)$ & 0.476 & & & \\
\hline \multicolumn{7}{|l|}{ Job Strain } \\
\hline Low & 0.00 & 1 & - & 0.00 & 1 & - \\
\hline High & 1.56 & $4.74(2.10,10.70)$ & $<0.001^{* * *}$ & 1.56 & $4.74(2.10,10.70)$ & $<0.001^{* * *}$ \\
\hline
\end{tabular}

${ }^{1}$ SLR $=$ Simple Logistic Regression $;{ }^{2}$ MLR $=$ Multiple Logistic Regression $;{ }^{* *}$ Significant at $\mathrm{p}<0.01 ;{ }^{* * *}$ Significant at $\mathrm{p}<0.001 ; \mathrm{N}=150 ;$ Hosmer-Lemeshow test, $(p=0.277)$, and area under the ROC curve $(73.2 \%)$ were applied to check the model fitness.

Results showed psychological job demand were significant predictor of depression $(\mathrm{OR}=8.08, \mathrm{p}<0.001)$, distress $(\mathrm{OR}=4.4, \mathrm{p}=0.012)$ using HADS-D and HAD-T respectively as well as DT $(\mathrm{OR}=6.09, \mathrm{p}=$ 0.032). High psychological job demand was capable of inducing depression and psychological distress. Similar to other studies which found that psychological job demand as an indicator for psychological morbidity disorders among workers and significant association found between job demand with psychological distress or mental illnesses $[8,9,28]$. Workers with high psychological job demand tend to get psychological distress, which seemed to also occur among breast cancer survivors [29].

Evidence showed decision latitude was significantly associated with psychological morbidity either with psychological job demand or on its own. Although, previous researches showed decision latitude was related with psychological disorders and served as a protective factor for distress [8] however, in this study, decision latitude was not a predictor and was not significantly related to anxiety, depression or distress as found by Bultmann, et al. [30].

Majority of respondents reported high level of social support $(51.3 \%)$, which meant that there were supports from their co-workers or supervisors. In this study, significant association was found between social support with depression and it served as a protective factor for depression $(\mathrm{OR}=0.39, \mathrm{p}=0.041)$. Similar to other studies [28,31], who also found that high social support was a protective factor as a buffered effect on psychological distress. Besides, Kawakami et al. [28] showed worksite support was an important factor which would influence job strain and also mental health. Workplace problems are usually related to poor interaction with colleagues and lack of support from co-workers and employers [32]. Positive social support encouraged them to return to work and hence reduced the risk of work disability or distress, as shown in some studies [33]. Those with high social support would have a low distress and better quality of life [34]. 
Table 6. Predictor of depression using HADS-D models.

\begin{tabular}{|c|c|c|c|c|c|c|}
\hline \multirow{2}{*}{ Variable } & \multicolumn{3}{|c|}{ SLR $^{1}$} & \multicolumn{3}{|c|}{ MLR $^{2}$} \\
\hline & $\mathrm{b}$ & Crude OR $(95 \% \mathrm{CI})$ & $\mathrm{p}$ & $\mathrm{b}$ & Adjusted OR $(95 \% \mathrm{CI})$ & $\mathrm{p}$ \\
\hline \multicolumn{7}{|l|}{ Employment } \\
\hline Government & 0.00 & 1 & - & & & \\
\hline Private & -0.70 & $0.50(0.20,1.25)$ & 0.138 & - & - & - \\
\hline Self-employed & -0.29 & $0.75(0.22,2.56)$ & 0.646 & & & \\
\hline \multicolumn{7}{|l|}{ Stage of cancer } \\
\hline Stage I & 0.00 & 1 & - & - & - & - \\
\hline Stage II & 0.43 & $1.53(0.66,3.57)$ & 0.323 & & & \\
\hline \multicolumn{7}{|l|}{ Psychological Job } \\
\hline Demand & 0.00 & 1 & - & 0.00 & 1 & - \\
\hline Low & 2.05 & $7.76(2.54,23.64)$ & $<0.001^{* * *}$ & 2.09 & $8.08(2.62,24.96)$ & $<0.001^{* * *}$ \\
\hline \multicolumn{7}{|l|}{ High } \\
\hline \multicolumn{7}{|l|}{ Decision Latitude } \\
\hline Low & 0.00 & 1 & - & - & - & - \\
\hline High & -0.12 & $0.89(0.40,1.99)$ & 0.774 & & & \\
\hline \multicolumn{7}{|l|}{ Social Support } \\
\hline Low & 0.00 & 1 & - & 0.00 & 1 & - \\
\hline High & -0.86 & $0.42(0.18,0.99)$ & $0.047^{*}$ & -0.93 & $0.39(0.16,0.96)$ & $0.041^{*}$ \\
\hline \multicolumn{7}{|l|}{ Job Insecurity } \\
\hline Low & 0.00 & 1 & - & - & - & - \\
\hline High & -0.08 & $1.08(0.48,2.44)$ & 0.86 & & & \\
\hline \multicolumn{7}{|l|}{ Job Strain } \\
\hline Low & 0.00 & 1 & - & - & - & - \\
\hline High & 1.66 & $5.24(2.22,12.41)$ & $<0.001^{* * *}$ & & & \\
\hline
\end{tabular}

Table 7. Predictor of psychological distress using HADS-T models.

\begin{tabular}{|c|c|c|c|c|c|c|}
\hline \multirow{2}{*}{ Variables } & \multicolumn{3}{|c|}{$\mathrm{SLR}^{1}$} & \multicolumn{3}{|c|}{ MLR $^{2}$} \\
\hline & $\mathrm{b}$ & Crude OR $(95 \% \mathrm{CI})$ & $\mathrm{p}$ & $\mathrm{b}$ & Adjusted OR $(95 \% \mathrm{CI})$ & $\mathrm{p}$ \\
\hline \multicolumn{7}{|l|}{ Employment } \\
\hline Government & 0.00 & 1 & - & & & \\
\hline Private & -0.60 & $0.55(0.23,1.33)$ & 0.184 & - & - & - \\
\hline Self-employed & -0.42 & $0.66(0.20,2.22)$ & 0.498 & & & \\
\hline \multicolumn{7}{|l|}{ Stage of cancer } \\
\hline Stage I & 0.00 & 1 & - & - & - & - \\
\hline Stage II & 0.51 & $1.66(0.74,3.72)$ & 0.222 & & & \\
\hline \multicolumn{7}{|c|}{ Psychological Job Demand } \\
\hline Low & 0.00 & 1 & - & 0.00 & 1 & - \\
\hline High & 1.98 & $7.25(2.62,20.08)$ & $<0.001^{* * *}$ & 1.48 & $4.40(1.38,13.99)$ & $0.012^{*}$ \\
\hline \multicolumn{7}{|l|}{ Decision Latitude } \\
\hline Low & 0.00 & 1 & - & - & - & - \\
\hline High & 0.04 & $1.04(0.48,2.26)$ & 0.912 & & & \\
\hline \multicolumn{7}{|l|}{ Social Support } \\
\hline Low & 0.00 & 1 & - & - & - & - \\
\hline High & -0.78 & $0.46(0.21,1.02)$ & 0.054 & & & \\
\hline \multicolumn{7}{|l|}{ Job Insecurity } \\
\hline Low & 0.00 & 1 & - & - & - & - \\
\hline High & -0.11 & $0.90(0.41,1.95)$ & 0.781 & & & \\
\hline \multicolumn{7}{|l|}{ Job Strain } \\
\hline Low & 0.00 & 1 & - & - & - & - \\
\hline High & 1.70 & $5.49(2.39,12.61)$ & $<0.001^{* * *}$ & & & \\
\hline
\end{tabular}


Table 8. Predictor of distress using DT models.

\begin{tabular}{|c|c|c|c|c|c|c|}
\hline \multirow{2}{*}{ Variables } & \multicolumn{3}{|c|}{$\mathrm{SLR}^{1}$} & \multicolumn{3}{|c|}{$\mathrm{MLR}^{2}$} \\
\hline & $\mathrm{b}$ & Crude OR (95\% CI) & $\mathrm{p}$ & $\mathrm{b}$ & Adjusted OR (95\% CI) & $\mathrm{p}$ \\
\hline \multicolumn{7}{|l|}{ Employment } \\
\hline Government & 0.00 & 1 & - & & & \\
\hline Private & -0.91 & $0.40(0.14,1.14)$ & 0.087 & - & - & - \\
\hline Self-employed & 0.01 & $1.01(0.29,3.56)$ & 0.991 & & & \\
\hline \multicolumn{7}{|l|}{ Stage of cancer } \\
\hline Stage I & 0.00 & 1 & - & - & - & - \\
\hline Stage II & 0.79 & $2.21(0.81,6.01)$ & 0.12 & & & \\
\hline \multicolumn{7}{|c|}{ Psychological Job Demand } \\
\hline Low & 0.00 & 1 & - & 0.00 & 1 & - \\
\hline High & 2.46 & $11.70(2.62,52.13)$ & $0.001^{* *}$ & 1.81 & $6.09(1.17,31.77)$ & $0.032^{*}$ \\
\hline \multicolumn{7}{|l|}{ Decision Latitude } \\
\hline Low & 0.00 & 1 & - & - & - & - \\
\hline High & -0.03 & $0.97(0.39,2.40)$ & 0.946 & & & \\
\hline \multicolumn{7}{|l|}{ Social Support } \\
\hline Low & 0.00 & 1 & - & - & - & - \\
\hline High & -0.95 & $0.39(0.15,1.01)$ & 0.053 & & & \\
\hline \multicolumn{7}{|l|}{ Job Insecurity } \\
\hline Low & 0.00 & 1 & - & - & - & - \\
\hline High & 0.12 & $1.12(0.45,2.82)$ & 0.804 & & & \\
\hline \multicolumn{7}{|l|}{ Job Strain } \\
\hline Low & 0.00 & 1 & - & 0.00 & 1 & - \\
\hline High & 1.98 & $7.21(2.73,19.07)$ & $<0.001^{* * *}$ & 1.16 & $3.17(1.07,9.05)$ & $0.037^{*}$ \\
\hline
\end{tabular}

In general population, high job strain was a common contributor to mental disorders such as anxiety, depression or distress [6,7]. However, job strain after returning to work among cancer survivors was not given attention with few studies focused on these. To date, only one study by Gudbergsson et al. [13] was carried out on job strain among primary-treated cancer survivors. The study found job strain was not related with survivorship but with socio-demographic, anxiety and personality trails. Similarly, this study showed $26 \%$ of the employed survivors had high job strain which was a significant predictor for anxiety and distress. However, none of the socio-demographic variable or cancer history was related to job strain and psychological distress. Just as other studies which found cancer diagnosis stage not significantly related to distress or psychiatric morbidity [21].

Little attention was given on job strain and distress by medical practitioners during their treatment follow-up, made it difficult to identify and recognized these problems among the cancer survivors. There might be also be other environmental factors which influenced psycho- logical morbidity such as family and diseases factors. This study had limitations in which the results were based on self-reported measures, thus, method bias, which resulted in shared variance of the measurement attributed to instrument rather than association between constructs might occurred. Sampling bias might also occur because unrandomized sampling. Work-related information on cancer cases are not easily available due to high unemployed rate of survivors, Only 150 survivors participated in this study. Besides these, respondents may have high tendency of denial or not being honest about their distress conditions to avoid being treated as mentally ill patients.

Improvement over treatment and diagnosis had led more researches to focus on psychological morbidity; however, factors contributing to distress were not emphasized. Future study should focus the detail aspects of job strain among cancer survivors who return to work after their treatment. An effective intervention and awareness on survivors' needs so as to overcome their distress level should be recommended to the health care 
workers, physician or social workers, to reduce the prevalence of distress or workplace stress as well as to encourage more survivors to return to work after cancer diagnosis and treatment, and at the same time increase their quality of life.

\section{Conclusion}

As a conclusion, among all workplace stressors studied, only psychological job demand, social support and job strain were factors that influenced distress among survivors. Survivors who experienced high psychological job demand, low social support and high job strain were reported with psychological distress. Psychological job demand and job strain were significant predictor for anxiety, depression, distress on both HADS-T and DT scales. While, social support served as a protective factor for depression.

\section{REFERENCES}

[1] S. Sauter, L. Murphy, M. Colligan, N. Swanson, J. Hurrell Jr., F. Scharf Jr., R. Sinclair, P. Grubb, L. Goldenhar, T. Alterman, J. Johnston, A. Hamilton and J. Tisdal, "Stress at Work," National Institute for Occupational Safety and Health, Cincinnati, 1999.

[2] M. Jarvis, "Teacher Stress: A Critical Review of Recent Findings and Suggestions for Future Research Directions," 2002.

http://www.isma.org.uk/stressnw/teachstress.htm

[3] J. P. Seward and R. C. Larsen, "Occupational and Environmental Medicine,” In: J. Ladou, Ed., Occupational and Environmental Medicine, McGraw Hill, New York, 2000, pp. 579-594.

[4] R. Karasek, N. Kawakami, C. Brisson, I Houtman, P. Bongers and B. Amick, "The Job Content Questionnaire (JCQ): An Instrument for Internationally Comparative Assessment of Psychosocial Job Characteristics," Journal of Occupational Health Psychology, Vol. 3, No. 4, 1998, pp. 322-355. doi:10.1037/1076-8998.3.4.322

[5] L. E. Bourne Jr. and R. A. Yaroush, "Stress and Cognition: A Cognitive Psychological Perspective," Unpublished Manuscript, NASA Grant NAG2-1561, 2003.

[6] S. Stansfeld and B. Candy, "Psychosocial Work Environment and Mental Health-A Meta-Analytic Review," Scandinavian Journal of Work Environment Health, Vol. 32, No. 6, 2006, pp. 443-462. doi:10.5271/sjweh. 1050

[7] R. Karasek and T. Theorell, "Healthy Work: Stress, Productivity and the Reconstruction of the Working Life," Basic Books, New York, 1990.

[8] S. Stansfeld, "Work, Personality and Mental Health," British Journal of Psychiatry, Vol. 181, No. 2, 2002, pp. 96-98.

[9] Z. A. Emilia and N. Hassim, "Work-Related Stress and Coping: A Survey on Medical and Surgical Nurses in a
Malaysian Teaching Hospital," Jabatan Kesihatan Masyarakat, Vol. 13, No. 1, 2007, pp. 55-66.

[10] J. A. Hansen, M. Feuerstein, L. C. Calvio and C. H. Olsen, "Breast Cancer Survivors at Work," Journal of Occupational and Environmental Medicine, Vol. 50, No. 7, 2008, pp. 777-784. doi:10.1097/JOM.0b013e318165159e

[11] A. M. Rahmat, "Malaysia and Breast Cancer," 2005. http://www.isnare.com/?aid=10518\&ca=Cancer+Survival

[12] A. G. E. M. de Boer, T. Taskila, A. Ojajarvi, F. J. H. van Dijk and J. H. A. M. Verbeek, "Cancer Survivors and Umployment. A Meta-Analysis and Meta-Regression," Journal of American Medical Association, Vol. 301, No. 7, 2009, pp. 753-762. doi:10.1001/jama.2009.187

[13] S. B. Gudbergsson, S. D. Fossa, B. Sanne and A. A. Dahl, "A Controlled Study of Job Strain in Primary-Treated Cancer Patients without Metastases," Acta Oncology, Vol. 46, No. 4, 2007, pp. 534-544. doi: $10.1080 / 02841860601156132$

[14] C. J. Bradley, H. L. Bednarek and D. Neumark, "Breast Cancer and Women's Labor Supply," Health Services Research Journal, Vol. 37, No. 5, 2002, pp. 1309-1328.

[15] A. Zigmond and P. R. Snaith, "The Hospital Anxiety and Depression Scale," Acta Psychiatrica Scandinavica, Vol. 67, 6, 1983, pp. 361-370. doi:10.1111/j.1600-0447.1983.tb09716.x

[16] M. Cohen, R. G. Hoffman, C. Cromwell, J. Schmeidler, F. Ebrahim, G. Carrera, F. Endorf, C. A. Alfonso and J. M. Jacobson, "The Prevalence of Distress in Persons with Human Immunodeficiency Virus Infection," Psychosomatics, Vol. 43, No. 1, 2002, pp. 10-15. doi:10.1176/appi.psy.43.1.10

[17] E. J. Shim, Y. W. Shin, H. J. Jeon and B. J. Hahm, "Distress and Its Correlates in Korean Cancer Patients: Pilot Use of the Distress Thermometer and the Problem List," Psycho-Oncology, Vol. 17, No. 6, 2008, pp. 548-555. doi: $10.1002 /$ pon. 1275

[18] NCCN-National Comprehensive Cancer Network, "Practice Guidelines in Oncology-V. Distress Management: National Comprehensive Cancer Network,” 2002.

[19] S. Ransom, P. B. Jacobsen and M. Booth-Jones, "Validation of the Distress Thermometer with Bone Marrow Transplant Patients," Psycho-Oncology, Vol. 15, No. 7, 2006, pp. 604-612. doi:10.1002/pon.993

[20] H. Zailina, H. W. Yong, M. S. Zalilah and H. Y. Yong, "Psychological Distress among Breast Cancer Survivors," In: M. S. Zalilah, H. Zailina, M. Kandiah and R. Asmah, Eds., Health and Nutrition of Cancer Survivors in Malaysia, Universiti Putra Malaysia Press, Serdang, 2011, pp. 88-101.

[21] N. Zainal, K. Hui, T. Hang and A. Bustam, "Prevalence of Distress in Cancer Patients Undergoing Chemotherapy," Asia-Pacific Journal of Clinical Oncology, Vol. 3, No. 4, 2007, pp. 219-223.

[22] L. Grassi, E. Rossi, S. Sabato, G. Cruciani and M. Zambelli, "Diagnostic Criteria for Psychosocial Variables in Breast Cancer," Psychosomatic, Vol. 45, No. 6, 2004, pp. 483-491. doi:10.1176/appi.psy.45.6.483 
[23] P. Lueboonthavatchai, "Prevalence and Psychosocial Factors of Anxiety and Depression in Breast Cancer Patients," Journal of Medical Association of Thailand, Vol. 90, No. 10, 2007, pp. 2164-2174.

[24] F. C. Atesci, B. Baltalarli, N. K. Oguzhanoglu, F. Karadag, O. Ozdel and N. Karagoz, "Psychiatric Morbidity among Cancer Patients and Awareness of Illness," Support Care Cancer, Vol. 12, No. 3, 2004, pp. 161-167. doi:10.1007/s00520-003-0585-y

[25] J. Y. Yen, C. H. Ko, C. F. Yen, M. J. Yang, C. Y. Wu, C. H. Juan and M. F. Hou, "Quality of Life, Depression and Stress in Breast Cancer Women Outpatients Receiving Active Therapy in Taiwan," Psychiatry Clinical Neurosciences, Vol. 60, No. 2, 2006, pp. 147-153. doi:10.1111/j.1440-1819.2006.01479.x

[26] S. Rosensfield, "The Effects of Women's Employment: Personal Control and Sex Differences in Mental Health," Journal of Health and Social Behavior, Vol. 30, No. 1, 1989, pp. 77-91. doi:10.2307/2136914

[27] T. A. Grady-Weliky, "Comorbidity and Its Implication on Treatment: Change over the Life Span," Syllabus and Proceedings Summary, American Psychiatric Association 2002 Annual Meeting, Philadelphia, 2002, p. 295.

[28] N. Kawakami and T. Naratani, "Epidemiology of Job Stress and Health in Japan: Review of Current Evidence and Future Direction," Industrial Health, Vol. 37, No. 2, 1999, pp. 174-186. doi:10.2486/indhealth.37.174

[29] K. Wilkins and M. P. Beaudet, "Work Stress and Health,"
Health Reports, Vol. 10, No. 3, 1998, pp. 47-62.

[30] U. Bultmann, I. J. Kant, P. A. van den Brandt and S. V. Kasl, "Psychosocial Work Characteristics as Risk Factors for the Onset of Fatigue and Psychological Distress: Prospective Results from the Maastricht Cohort Study," Psychological Medicine, Vol. 32, No. 2, 2002, pp. 333345. doi:10.1017/S0033291701005098

[31] R. Karasek, B. Gardell and J. Lindell, "Work and NonWork Correlated of Illness and Behaviours in Male and Female Swedish White Collar Workers," Journal of Occupational Behavior, Vol. 8, No. 3, 1987, pp. 187-207. doi:10.1002/job.4030080302

[32] E. Maunsell, C. Brisson, L. Dubois, S. Lauzier and A. Fraser, "Work Problems after Breast Cancer: An Exploratory Qualitative Study," Psycho-Oncology, Vol. 8, No. 6, 1999, pp. 467-473.

doi:10.1002/(SICI)1099-1611(199911/12)8:6<467::AIDPON400>3.0.CO;2-P

[33] E. Spelten, M. Sprangers and J. Verbek, "Factors Reported to Influence The Return to Work of Cancer Survivors: A Literature Review," Psycho-Oncology, Vol. 11, No. 2, 2002, pp. 124-131. doi:10.1002/pon.585

[34] F. Ogce, S. Ozkan and B. Baltalarli, "Psychosocial Stressors, Social Support and Socio-Demographic Variables as Determinants of Quality of Life of Turkish Breast Cancer Patients," Asian Pacific Journal of Cancer Prevention, Vol. 8, No. 1, 2007, pp. 77-82. 